\title{
Long-term effects of CPAP on daytime functioning in patients with sleep apnoea syndrome
}

\author{
A. Muñoz*, L.R. Mayoralas*, F. Barbé*, J. Pericás**, A.G.N. Agustí*
}

Long-term effects of CPAP on daytime functioning in patients with sleep apnoea syndrome. A. Muñoz, L.R. Mayoralas, F. Barbé, J. Pericás, A.G.N. Agustí. (C)ERS Journals Ltd 2000. ABSTRACT: Daytime sleepiness, impaired cognitive performance and dysphoric mood are often present in patients with obstructive sleep apnoea syndrome (SAS). This prospective controlled study evaluates the effects of treatment with continuous positive airway pressure (CPAP) during $1 \mathrm{yr}$ on daytime functioning in a large group of patients with SAS.

The authors studied 80 patients (mean \pm SEM $49 \pm 1$ yrs) with SAS with a mean apnoea-hypopnoea index of $60 \pm 2 \mathrm{~h}^{-1}$, and 80 healthy control subjects matched for sex and age (46 \pm 1 yrs.). Measurements were obtained at the beginning of the study and $12 \pm 1$ months later, and included: daytime sleepiness (Epworth scale), depression and anxiety (Beck tests), vigilance (Steer-Clear $($ ) ) and reaction time (Psychometer Vigilance Test $192 \AA)$. Drug, coffee and alcohol intake, as well as the sleep schedule, were also recorded.

Results showed that, before treatment, patients were more somnolent $(\mathbf{p}<0.001)$, anxious $(p<0.01)$ and depressed $(p<0.001)$ than control subjects. Also, they had a longer reaction time $(p<0.05)$ and poorer vigilance $(p<0.01)$. The use of CPAP improved significantly the levels of somnolence $(p<0.0001)$ and vigilance $(p<0.01)$, but failed to modify anxiety and depression. Reaction time changes were minor. Variables with a potential confounding effect did not change during the study.

These results provide firm evidence to substantiate the use of continuous positive airway pressure in patients with sleep apnoea syndrome.

Eur Respir J 2000; 15: 676-681.
* Servei Pneumología, Hospital Universitari Son Dureta, Palma de Mallorca, Spain. **Escola Infermeria, Universitat Illes Balears, Palma de Mallorca, Spain.

Correspondence: A.G.N. Agustí

Servei de Pneumologia

Hospital Universitari Son Dureta 07014 Palma de Mallorca

Spain

Fax: 34971175228

Keywords: Continuous positive airway pressure, reaction time, sleep apnoea syndrome, sleepiness, vigilance

Received: July 151999

Accepted after revision January 192000

Supported, in part, by Dirección General de Trafico, Carburos Metálicas and Associacio Balear per L'Estudi de les Malalties Respiratories
Patients with sleep apnoea syndrome (SAS) often complain of several deficits in neuropsychological performance at consultation. For instance, daytime sleepiness is a hallmark of the disease. Furthermore, dysphoric mood and abnormal cognitive performance are not uncommon in these patients [1-6]. Finally, NAËGELÉ et al. [7] showed in a controlled study that patients with SAS often present memory deficits and frontal lobe related abnormalities.

Clinical experience has shown that the use of nasal continuous positive airway pressure (CPAP) in patients with SAS is very effective in improving these symptoms. However, previous studies aimed at objectively assessing these effects were often uncontrolled $[8,9]$, included a small number of patients and/or were of short duration [10-17]. This had lead some authors to question the usefulness of CPAP treatment in patients with SAS [18].

To provide firm evidence on the long-term effects of CPAP upon neuropsychological function in patients with SAS, the current authors designed a prospective controlled study that evaluated the effects of $1 \mathrm{yr}$ of treatment with CPAP upon cognitive performance, daytime sleepiness and mood in a large group $(n=80)$ of such patients.

\section{Material and methods}

\section{Population}

Patients were recruited prospectively from all those attending the sleep unit of the Hospital Universitari Son
Dureta from November 1995 until April 1997. The inclusion criteria were: 1) had more than 20 apnoeas-hypopnoeas per hour of sleep (recorded during a full, supervised, standard polysomnographic study (Ultrasom Nicolette; Madison, WI, USA)); 2) required treatment with nasal CPAP, according to the criteria proposed by the Spanish Society of Pulmonology and Thoracic Surgery. These criteria recommend active treatment with CPAP whenever the apnoea-hypopnoea index is $>20 \cdot \mathrm{h}^{-1}$ and there are clear symptoms of the disease and/or the patient has cardiovascular disease [19]; 3) lived permanently in Mallorca, Spain (to facilitate follow-up); and 4) had $>8$ yrs of school education (to allow the performance of some of the psychological tests used in the study). Candidates were excluded if they were drug abusers, had a psychiatric disorder, were shift-workers, and/or had been previously diagnosed of epilepsy, narcolepsy and/or periodic leg movements disease. Eighty-nine potential candidates were screened and nine were excluded (three shift-workers, two psychiatric disorders, one epilepsy, one periodic leg movements disease, one nonpermanent resident in Mallorca, and one who refused to participate). Finally, 80 patients (78 males) were included in the study.

The control subjects were nonmedical workers or visitors to the Hospital Universitari Son Dureta referred by faculty members of the authors' institution, not directly involved in the study; patient relatives were specifically excluded. Control subjects were individually matched with patients for age $( \pm 5 \mathrm{yrs})$ and sex. Their inclusion and 
exclusion criteria were the same as mentioned above for patients, except for the presence of SAS. This was excluded clinically [20] or, if necessary, after a full polysomnography. Eighty-two volunteers were screened, in whom three polysomnographic studies were required. SAS was diagnosed in two of these three individuals, who were accordingly excluded. Hence, a total of 80 healthy control subjects (78 males) were finally included in the study.

The protocol was approved by the Ethics Committee of the authors' institution. All participants signed their written consent after being fully aware of the aims, nature and characteristics of the study.

\section{Study design}

In all participants (patients and control subjects), measurements were obtained at the beginning of the study and $12 \pm 1$ months later. In patients, but not in control subjects, measurements were also obtained $3 \pm 0.1$ months after the initiation of CPAP treatment.

\section{Measurements}

The authors used a standardized questionnaire to record data on occupation, previous medical conditions, use of drugs, number of hours of sleep per day, and alcohol and coffee intake. The degree of subjective sleepiness was measured with the Epworth scale [21] and the level of anxiety and depression with the Beck questionnaires [22]. Reaction time was explored using the Psychometer Vigilance Test (PVT 192®); CWE, Inc., Ardmore, PA, USA) [23]. This device incorporates a red light that flashes at random intervals during the test $(\sim 80-85$ times in 10 min). Subjects were asked to press a button as soon as they realized that the red light has flashed. The period of time elapsed between these two events (reaction time) was recorded in a computer for later analysis, following the methodology previously reported in the authors' laboratory [24]. The test was performed, between 10:0012:00 $\mathrm{h}$. The level of vigilance was investigated using the Steer-Clear $\mathbb{R}$ test (Findley \& Fabricio, Charlottesville, VA, USA) [25], also between 10:00-12:00 h.

Briefly, for $30 \mathrm{~min}$, subjects were asked to sit in front of a computer screen showing a small car running through a long, linear road. Unexpectedly, at random intervals, an object (steer) appeared in the road. The individual had to press the space bar to avoid hitting the steer. As previously reported [24], the test was set such that 500 steers appeared during the $30 \mathrm{~min}$ duration. The number of hits was recorded by the computer every minute. For each subject, data was later analysed and expressed both in absolute values (during the initial and final parts of the test) and also as the percentage of hits during the whole duration of the test. Compliance with CPAP was assessed with the time counter built up in each CPAP device (REMstar; Respironics, Monroeville, PA, USA).

\section{Statistical analysis}

Results are shown as mean \pm SEM. For discrete variables, differences between groups were investigated by the Chi- squared test. For continuous variables, the statistical significance of differences was first assessed using a two-way analysis of variance (ANOVA). If significant, a one-way ANOVA was then used to evaluate the effects of CPAP through time in patients, while a paired t-test was used to investigate potential changes in control subjects. Differences between groups at any given point in time were investigated using a t-test for independent samples. The significance of changes in neuropsychological variables was also assessed by the calculation of the effect sizes [26]. An effect size of 0.2 is considered small, 0.5 medium and 0.8 large [17]. The association between CPAP compliance and the change with time of different variables of interest was explored using the Pearson correlation test. Statistical significance was accepted at $\mathrm{p}<0.05$.

\section{Results}

\section{Data at baseline}

Table 1 shows the main anthropometric data of all participants at the beginning of the study. Patients were slightly but significantly older than control subjects. However, the difference was of marginal biological relevance. As expected, patients were more obese than control subjects $(\mathrm{p}<0.01)$. Also, both the systolic and diastolic blood pressure levels were higher $(p<0.01)$ in patients. The severity of SAS in patients ranged from mild (21 apnoeas/ hypopnoeas $\left.\cdot \mathrm{h}^{-1}\right)$ to severe $\left(123\right.$ apnoeas-hypopnoeas $\left.\cdot \mathrm{h}^{-1}\right)$ with a mean apnoea-hypopnoea index of $60 \pm 2 \cdot \mathrm{h}^{-1}$. The lowest nocturnal oxygen saturation was $64 \pm 2 \%$.

Table 2 presents the values of some potentially confounding variables recorded in patients and control subjects. The same number of individuals received treatment with b-blockers (three versus one) and, oral antidiabetics (five versus three) in both groups, although benzodiazepines (eight versus two, $\mathrm{p}=0.05$ ) and antidepressant drugs (five versus zero, $\mathrm{p}<0.05$ ), were consumed more often in patients than in control subjects. Alcohol consumption was similar (and modest) in both groups (table 2), but patients consumed slightly higher quantities than control subjects during the weekend $(\mathrm{p}<0.05)$. Coffee intake and number of hours of reported sleep per day were similar in patients and control subjects (table 2).

Before CPAP, patients were more depressed and anxious than control subjects (table 3, fig. 1). In absolute terms, though, these values are only moderately abnormal [22]. As expected, patients were more somnolent than healthy

Table 1. - Anthropometric data of all participants at baseline

\begin{tabular}{lcc}
\hline & Patients & Control subjects \\
\hline $\mathrm{n}$ & 80 & 80 \\
Age yrs & $49 \pm 1$ & $46 \pm 1^{*}$ \\
Sex M/F & $78 / 2$ & $78 / 2$ \\
Body mass index $\mathrm{kg} \cdot \mathrm{m}^{-2}$ & $33 \pm 1$ & $26 \pm 0.4^{* *}$ \\
Systolic blood pressure $\mathrm{mmHg}$ & $132 \pm 2$ & $124 \pm 2^{* *}$ \\
Diastolic blood pressure $\mathrm{mmHg}$ & $84 \pm 2$ & $76 \pm 1^{* *}$ \\
\hline
\end{tabular}

Data are expressed as mean \pm SEM. M: male; F: female. *: $\mathrm{p}<0.05$; **: $\mathrm{p}<0.01$, compared to patients. $1 \mathrm{mmHg}=0.133 \mathrm{kPa}$. 
Table 2. - Mean \pm SEM of some potentially relevant confounding variables at baseline

\begin{tabular}{|c|c|c|}
\hline & Patients & Control subjects \\
\hline $\mathrm{n}$ & 80 & 80 \\
\hline Benzodiazepine use & 8 & 2 \\
\hline Antidepressant use & 5 & $0 *$ \\
\hline \multicolumn{3}{|l|}{ Alcohol consumption $\mathrm{g} \cdot \mathrm{day}^{-1}$} \\
\hline Mean daily dose & $15 \pm 3$ & $11 \pm 2$ \\
\hline Mean dose during the weekend & $30 \pm 4$ & $20 \pm 2 *$ \\
\hline Coffee intake cups $\cdot$ day $^{-1}$ & $2 \pm 0.2$ & $2 \pm 0.2$ \\
\hline Number of hours of sleep $\cdot$ day $^{-1}$ & $8 \pm 0.2$ & $8 \pm 0.2$ \\
\hline
\end{tabular}

*: $\mathrm{p}<0.05$ compared to patients.

control subjects (table 3, fig. 1). Table 3 also shows that patients had higher reaction time values and performed

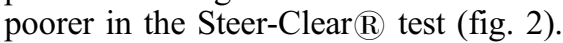

\section{Follow-up}

Some patients and control subjects were lost during follow-up. After 3 months, the authors were able to evaluate 74 patients. At the end of the study $(12 \pm 1$ months $)$ 71 patients and 63 control subjects could be investigated. The only reason for losing patients and control subjects for follow-up was their reluctance to continue in the study. In no case was follow-up lost due to a medical reason. The anthropometric characteristics and the severity of the disease in patients lost for follow-up was not different from those investigated during the rest of the study period.

At this point in time, differences in body mass index between patients and control subjects persisted unaltered with respect to the initiation of the study $(32 \pm 0.6$ versus $\left.27 \pm 0.5 \mathrm{~kg} \cdot \mathrm{m}^{-2}, \mathrm{p}<0.001\right)$. Three patients and two control subjects consumed benzodiazepines and four patients and one control subject consumed antidepressant drugs $(p=N s)$. Alcohol and coffee intake did not change in any group during the course of the study. Finally, the number of hours of reported sleep per night remained unchanged $(8 \pm 0.1$ versus $8 \pm 0.3 \mathrm{~h}$ ). On average, patients used CPAP for $5.8 \pm 0.2 \mathrm{~h} \cdot$ night $^{-1}$, although individual compliance ranged $0.4-10.95 \mathrm{~h}$.

Figures 1 and 2 present the evolution through time of the main neuropsychological variables assessed in the study. None of these variables changed significantly within the control group. This was not the case in patients with

Table 3. - Clinical and laboratory data in all participants at baseline

\begin{tabular}{|c|c|c|}
\hline & Patients & $\begin{array}{l}\text { Control } \\
\text { subjects }\end{array}$ \\
\hline $\mathrm{n}$ & 80 & 80 \\
\hline Somnolence Epworth scale & $12 \pm 1$ & $3 \pm 2 * * *$ \\
\hline Depression score Beck test & $8 \pm 1$ & $4 \pm 1 * * *$ \\
\hline Anxiety score Beck test & $8 \pm 1$ & $5 \pm 1 * *$ \\
\hline 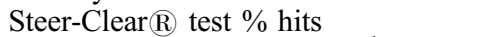 & $2.5 \pm 1$ & $0.4 \pm 0.06^{* *}$ \\
\hline Steer-Clear $\mathbb{R}$ test $0-15 \cdot \mathrm{min}^{-1}$ steers & $4.1 \pm 1$ & $1.2 \pm 0.2^{*}$ \\
\hline Steer-Clear $\mathbb{R}$ test $15-30 \cdot \mathrm{min}^{-1}$ steers & $6.1 \pm 1.6$ & $1.1 \pm 0.2 * *$ \\
\hline Reaction time ms & $280 \pm 5$ & $264 \pm 4 *$ \\
\hline
\end{tabular}

Data are expressed as mean \pm SEM. *: $\mathrm{p}<0.05 ; * *: \mathrm{p}<0.01 ; * * *$ : $\mathrm{p}<0.001$, compared to patients.
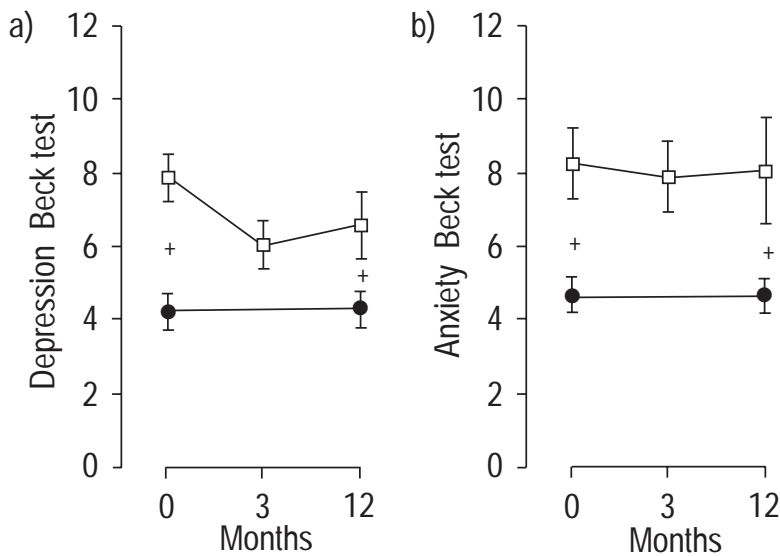

Fig. 1. - Mean \pm SEM values of depression (a) and anxiety (b) scores measured in patients (at 0,3 and 12 months $(O)$ ) and control subjects (at 0 and 12 months (O)) during follow-up. Note that there is no effect of treatment during follow-up in patients with sleep apnoea syndrome. ${ }^{+}$: $\mathrm{p}<0.05$ between groups at given points in time; $\mathrm{p}=\mathrm{NS}$ for two-way analysis of variance in both tests.

SAS, in whom some variables changed very significantly while, interestingly, others did not. Depression and anxiety scores were amongst those variables not influenced by treatment (fig. 1). In contrast, the levels of somno-

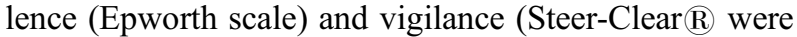
significantly improved by CPAP (fig. $2 \mathrm{a}$ and c). Such an improvement was already evident after 3 months of treatment and tended to improve further after $12 \pm 1$ months. The Epworth scale improved further (slightly but significantly) from month 3 to month 12 (from $5.8 \pm 0.4$ to $4.3 \pm 0.4, p<0.05)$. Finally, differences in reaction time failed to reach statistical significance (two-way ANOVA), but values in patients tended to normalize with time and, the difference that was observed with the control group before treatment disappeared after CPAP (fig. 2b). Table 4 presents the analysis of the effect sizes. None of the
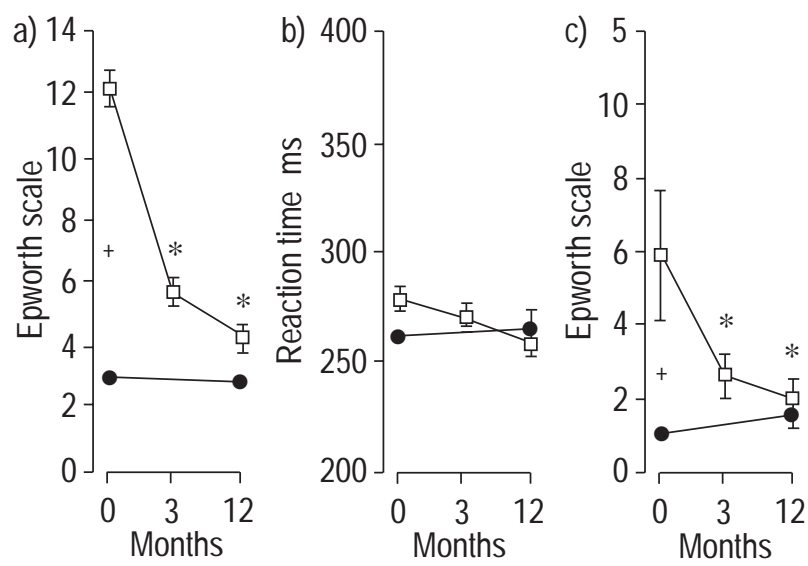

Fig. 2. - Mean \pm SEM values of somnolence (as assessed by the Ep-

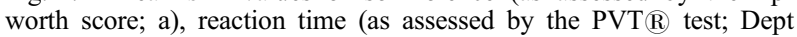
Psychiatry, University of Pennsylvania, PA, USA; b), and vigilance (as assessed by the Steer-Clear $\mathbb{R}$ test; $c$ ) measured in patients (at 0,3 and 12 months $(\bigcirc)$ ) and control subjects (at 0 and 12 months $(\mathbf{O})$ ) during follow-up. Note that treatment with continuous positive airway pressure improves somnolence and the Steer-Clear $\mathbb{R}$ performance (but not reaction time) in patients with sleep apnoea syndrome $*$ : $p<0.05$ with respect to the values measured at month $=0 ;{ }^{+}: \mathrm{p}<0.05$ between groups at given points in time. The $\mathrm{p}$-values from two-way analysis of variance where: a: $p<0.0001$; : NS; c: $p<0.01$ 
Table 4. - Effect sizes of the observed changes at 12 months of follow-up in the two groups of subjects studied

\begin{tabular}{lcc}
\hline & Patients & Control subjects \\
\hline $\mathrm{n}$ & 72 & 63 \\
Somnolence Epworth scale & 3.76 & $0.16^{* * *}$ \\
Depression score Beck test & 0.19 & 0.02 \\
Anxiety score Beck test & 0.1 & 0.01 \\
Steer-Clear $\AA$ test \% hits & 1.57 & $-0.22^{*}$ \\
Hits 0-15. $\mathrm{min}^{-1}$ & 1.06 & $-0.12^{\#}$ \\
Hits 15-30·min & 0.89 & $-0.25^{* *}$ \\
Reaction time ms & 0.27 & -0.18 \\
\hline
\end{tabular}

*: $\mathrm{p}<0.05 ; * *: \mathrm{p}<0.01 ; * * *$ p $<0.001$, compared to patients. ${ }^{*}$ : $\mathrm{p}=0.06$.

changes observed in the control group were greater than 0.2 (the minimum threshold value to consider it biologically relevant) [17]. In contrast, several of the variables show an effect size $>0.8$ in the patients with SAS, indicating a large biological effect [17]. Differences between groups reached statistical significance in these same variables (table 4).

Finally, the authors explored the relationship between the compliance with CPAP treatment and the changes observed in the above mentioned variables after $12 \pm 1$ months on CPAP. It was found that the former was significantly related to the improvement of somnolence (fig. 3). Interestingly, changes in Steer-Clear $\mathbb{R}$ performance were not related to the level of compliance with CPAP treatment. Also, the lack of changes in the remaining variables analysed in this study (depression, anxiety and reaction time) explains the absence of a significant relationship with CPAP compliance.

\section{Discussion}

The results of this large, long-term, prospective controlled study provide firm evidence to substantiate the use of CPAP in patients with SAS. Specifically, they show that the long-term use of CPAP significantly improves the levels of somnolence and vigilance, that these changes are already evident after 3 months of treatment, that they

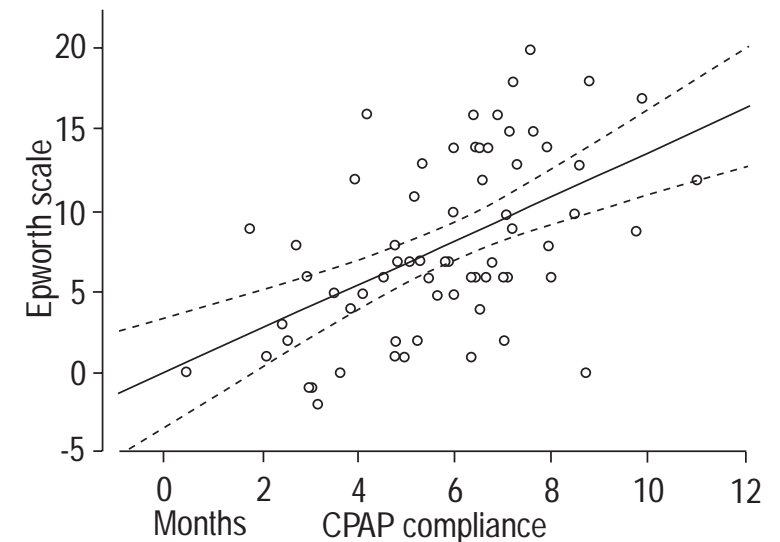

Fig. 3. - Positive correlation $(r=0.52, p<0.0001)$ between the compliance with continuous positive airway pressure (CPAP) treatment in each patient $(O)$ and the improvement seen in the degree of somnolence (as assessed by the Epworth scale) after $12 \pm 1$ months on CPAP. correlation line; - - : : 95\% confidence interval. persist after $12 \pm 1$ months on CPAP, and that they are not explained by the presence of some potentially confounding variables. Interestingly, however, they also show that the long-term use of CPAP does not normalize the levels of depression and anxiety seen in these patients.

The present study has several potential limitations that deserve comment. Firstly, it was not a randomized study. In theory, the ideal experimental design should probably have considered the randomization of patients with SAS to receive treatment with CPAP or placebo (sham CPAP) [27]. However, this was considered unethical because of the severity of the disease in the patients included (mean

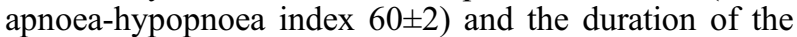
study (1 yr follow-up). Secondly, the control group does exclude a learning effect but cannot exclude a possible placebo effect. However, the correlation observed between the use of CPAP and the change in somnolence (dose/effect relationship; fig. 3 ) is an argument against the latter.

SAS is associated with a variety of neuropsychological effects $[6,7,9,13,28-31]$. The present study confirms that, before treatment, patients with SAS were more anxious, depressed and somnolent than matched healthy control subjects (table 3, figs. 1 and 2). Also, these patients had a higher reaction time and a lower level of vigilance (fig. 2). These latter observations confirm previous results from the authors' laboratory [24].

It is widely accepted that CPAP treatment may be beneficial in patients with SAS for a variety of reasons [32]. Recently, however, some authors have claimed that the evidence sustaining these potentially beneficial effects of CPAP in SAS is weak [18]. Previous studies investigating the effects of CPAP on neuropsychological performance in SAS, were typically of short duration (weeks) and normally included only a small number of subjects $[10-12,14,15]$. With these limitations in mind, the results of these previous studies consistently show that CPAP improves sleepiness, vigilance, mental flexibility, attention, mood, functional status, general health and energy/fatigue in patients with mild, moderate and severe SAS $[10-12,14,15,17]$. The results of the present study at 3 months (figs. 1 and 2) confirm these previous reports [33]. However, by including a larger population of patients (and a matched control group), as well as by following-up these individuals during a much longer period of time (12 \pm 1 months), the current findings strengthen the validity of these conclusions and extend them to a chronic situation. Accordingly, therefore, the results of this study provide firm evidence on which to substantiate the use of CPAP in patients with SAS. Furthermore, the analysis of the effect sizes of the observed changes (table 4) support this interpretation.

It was somewhat surprising to find out that CPAP did not improve the depression and anxiety scores, either at short or long-term (fig. 1). However, this observation is in keeping with a previous study assessing its effects in the short-term [12]. To explain these observations, several potential explanations can be considered. Low compliance with treatment can be excluded as a potential cause because, on average, this was quite acceptable $(5.8 \pm 0.2$ $\mathrm{h} \cdot$ night $\left.^{-1}\right)$. It is possible that the questionnaires used in the study lacked discriminatory value to identify small differences after treatment. However, the authors think that this possibility is unlikely because of the magnitude of the 
observed differences (fig. 1). Alternatively, anxiety and depression in SAS may not be causally related to the number of apnoeas at night, which is the physiological event most dramatically improved by CPAP [34]. Yet, the observed correlation between CPAP compliance and somnolence improvement (fig. 3) also makes this possibility unlikely. It is possible that the chronic use of CPAP can generate anxiety and depression by itself. If so, this would counteract any potential improvement derived from the actual treatment of SAS. Finally, patients may remain anxious and depressed despite the use of CPAP because they are aware of the fact that this is a symptomatic, rather than curative, treatment. In any case, it should be remembered that the absolute level of depression and anxiety depicted by patients (fig. 1), although clearly different from control subjects is only mild to moderate in severity [22].

In summary, this study demonstrates that the use of continuous positive airway pressure in patients with sleep apnoea syndrome improves sleepiness and vigilance, both in the short and long-term. Continuous positive airway pressure does not improve the levels of anxiety or depression seen in these patients. Changes in reaction time were of small magnitude and of questionable clinical relevance.

\footnotetext{
Acknowledgements. The authors thank $H$.
} Engleman (University of Edinburgh, Scotland, UK) for statistical advice.

\section{References}

1. Johns MW. Daytime sleepiness, snoring, and obstructive sleep apnea: the Epworth sleepiness scale. Chest 1993; 103: 30-36.

2. Strohl KP, Bonnie RJ, Findley L, et al. Sleep apnea, sleepiness, and driving risk. Am J Respir Crit Care Med 1994; 150: 1463-1473.

3. Telakivi T, Kajaste S, Partinen M, Brander P, Nyholm A. Cognitive function in obstructive sleep apnea. Sleep 1993; 16: S74-S75.

4. Bonnet MH. Vigilance/sleepiness sequelae of sleep disordered breathing and sleep apnea. Cognitive effects of sleep and sleep fragmentation. Sleep 1993; 16: S65-S67.

5. Jennum P, Sjol A. Self-assessed cognitive function in snorers and sleep apneics. An epidemiological study of 1,504 females and males aged 30-60 years. The DanMONICA II study. Eur Neurol 1994; 34: 204-208.

6. Bédard MA, Montplaisir J, Richer F, Rouleau I, Malo J-L. Obstructive sleep apnea syndrome pathogenesis of neuropsychological deficits. J Clin Exp Neuropsychol 1991; 13: 950-964.

7. Naëgelé B, Thouvard V, Pépin J-L, et al. Deficits of cognitive executive functions in patients with sleep apnea syndrome. Sleep 1995; 18: 43-52.

8. Kotterba S, Rasche K, Widdig W, et al. Neuropsychological investigations and event-related potentials in obstructive sleep apnea syndrome before and during CPAP-therapy. J Neurol Sci 1998; 159: 45-50.

9. Naëgelé B, Pépin JL, Levy P, Bonnet C, Pellat J, Feuerstein C. Cognitive executive dysfunction in patients with obstructive sleep apnoea syndrome (OSAS) after CPAP treatment. Sleep 1998; 21: 392-397.

10. Ballester E, Badia JR, Hernandez L, et al. Evidence of the effectiveness of continuous positive airway pressure in the treatment of sleep apnea/hypopnea syndrome. $A m J$ Respir Crit Care Med 1999; 159: 495-501.

11. Engleman HM, Kingshott RN, Wraith PK, Mackay TW, Deary IJ, Douglas NJ. Randomized placebo-controlled crossover trial of continuous positive airway pressure for mild sleep apnea/hypopnea syndrome. Am J Respir Crit Care Med 1999; 159: 461-467.

12. Engleman HM, Martin SE, Deary IJ, Douglas NJ. Effect of continuous positive airway pressure treatment on daytime function in sleep apnoea/hypopnoea syndrome. Lancet 1994; 343: 572-575.

13. Engleman HM, Martin SE, Deary IJ, Douglas NJ. Effect of CPAP therapy on daytime function in patients with mild sleep apnoea/hypopnoea syndrome. Thorax 1997; 52: 114-119.

14. Engleman HM, Martin SE, Kingshott RN, Mackay TW, Deary IJ, Douglas NJ. Randomized placebo controlled trial of daytime function after continuous positive airway pressure (CPAP) therapy for the sleep apnoea/hypopnoea syndrome. Thorax 1998; 53: 341-345.

15. Redline S, Adams N, Strauss ME, Roebuck T, Winters $\mathrm{M}$, Rosenberg C. Improvement of mild sleep-disordered breathing with CPAP compared with conservative therapy. Am J Respir Crit Care Med 1998; 157: 858-865.

16. Kiely JL, Murphy M, McNicholas WT. Subjective efficacy of nasal CPAP therapy in obstructive sleep apnoea syndrome: a prospective controlled study. Eur Respir $J$ 1999; 13: 1086-1090.

17. Jenkinson C, Davies RJO, Mullins R, Stradling JR. Comparison of therapeutic and subtherapeutic nasal continuous positive airway pressure for obstructive sleep apnoea: a randomized prospective parallel trial. Lancet 1999; 353: 2100-2105.

18. Wright J, Johns R, Watt I, Melville A, Sheldon T. Health effects of obstructive sleep apnoea and the effectiveness of continuous positive airways pressure: A systematic review of the research evidence. BMJ 1997; 314: 851860.

19. Marin JM, Aran X, Barbé F, et al. Normativa sobre diagnostico y tratamiento del sindrome de apnea obstructiva del sueffo (SAOS). SEPAR 1993; 14: 1-24.

20. Kapuniai LE, Andrew DJ, Crowell DH, Pearce JW. Identifying sleep apnea from self-reports. Sleep 1988; 11: 430-436.

21. Johns MW. A new method for measuring daytime sleepiness: the Epworth sleepiness scale. Sleep 1991; 14: 540545.

22. Beck AT. Depression: clinical experimental and theoretical aspects. New York, NY, USA, Harper \& Row, 1970.

23. Dinges DF, Kribbs NB. Performing while sleepy: effects of experimentally-induced sleepiness. In: Monk TH, eds. Sleep, sleepiness and performance. Chichester, UK, John Wiley \& sons Ltd, 1991; pp. 97-128.

24. Barbé F, Pericás J, Muñoz A, et al. Automobile accidents in patients with sleep apnea syndrome - an epidemiological and mechanistic study. Am J Respir Crit Care Med 1998; 158: 18-22.

25. Findley L, Fabricio M, Knight H, Norcross BB, Laforte AJ, Suratt P. Driving simulator performance in patients with sleep apnea. Am Rev Respir Dis 1989; 140: 529-530.

26. Kazis LE, Anderson JJ, Meenan RF. Effect sizes for interpreting changes in health status. Med Care 1989; 27 : S178-189.

27. Farré R, Hernandez L, Montserrat JM, Rotger M, Ballester E, Navajas D. Sham continuous positive airway 
pressure for placebo-controlled studies in sleep apnea. Lancet 1999; 353: 1154.

28. Cheshire K, Engleman H, Deary I, Shapiro C, Douglas NJ. Factors impairing daytime performance in patients with sleep apnea/hypopnea syndrome. Arch Intern Med 1992; 152: 538-541.

29. Engleman HM, Cheshire KE, Deary IJ, Douglas NJ. Daytime sleepiness, cognitive performance and mood after continuous positive airway pressure for the sleep apnoea/hypopnoea syndrome. Thorax 1993; 48: 911914.

30. Kingshott RN, Sime PJ, Engleman HM, Douglas NJ. Self assessment of daytime sleepiness: patient versus partner. Thorax 1995; 50: 994-995.
31. Montplaisir J, Bédard M, Richer F, Rouleau I. Neurobehavioural manifestations in obstructive sleep apnoea syndrome before and after treatment with continuous positive airway pressure. Sleep 1992; 15: s17-s19.

32. Douglas NJ. Systematic review of the efficacy of nasal CPAP. Thorax 1998; 53: 414-415.

33. McArdle N, Devereux G, Heidarnejad H, Engleman HM, Mackay TW, Douglas NJ. Long-term use of CPAP therapy for sleep apnea/hypopnea syndrome. Am J Respir Crit Care Med 1999; 159: 1108-1114.

34. Sullivan CE, Berthon-Jones M, Issa FG, Eves L. Reversal of obstructive sleep apnoea by continuous positive airway pressure applied through the nares. Lancet 1981; 1: 862-865. 